\title{
Circulating and deposited immune complexes in renal disease and their clinical correlation
}

\author{
S. L. COHEN 1 , C. FISHER ${ }^{2}$, J. F. MOWBRAY ${ }^{3}$, A. HOPP 2 , AND J. BURTON-KEE \\ From the Departments of ${ }^{1}$ Medicine and ${ }^{2}$ Morbid Anatomy, University College Hospital Medical School, \\ University Street, London WCIE 6JJ, and the ${ }^{3}$ Department of Experimental Pathology, \\ St Mary's Hospital Medical School, London W2 INY, UK
}

SUMMARY In 48 patients undergoing renal biopsy there was a strong correlation $\left(\chi^{2} 11 \cdot 45(\mathrm{P}<0 \cdot 01)\right)$ between the demonstration of circulating and deposited immune complexes. Serial studies of circulating immune complex levels have shown fluctuations which only sometimes appear to coincide with clinical changes in individual patients.

The presumed importance of circulating immune complexes (CIC) in the pathogenesis of glomerulonephritis in man is based on comparisons with animal models (Wilson and Dixon, 1976).

There is much indirect evidence suggesting the activity of immune complexes in human glomerulonephritis from (i) demonstration of granular deposits of immunoglobulins and complement components in renal biopsy sections by immunofluorescence, (ii) changes in serum complement levels, and (iii) detection of complement breakdown products in the circulation as well as cryoglobulins and rheumatoid factor. A number of workers have described varying levels of $\mathrm{CIC}$ in several histological types of glomerulonephritis (Johnson et al., 1975; Rossen et al., 1976; Stühlinger et al., 1976; Ooi et al., 1977; Woodroffe et al., 1977; Cohen et al., 1978; Levinsky et al., 1978; Onyewotu and Mee, 1978; Pussell et al., 1978). The purpose of this study was $(a)$ to investigate whether CIC could be detected at the time of renal biopsy and correlated with histological findings, and $(b)$ to see if serial measurements of levels of CIC indicated any correlation with the clinical course.

\section{Methods}

\section{DETECTION OF CIRCULATING IMMUNE \\ COMPLEXES}

Blood samples were taken in the morning and allowed to clot at room temperature. Sera were stored at $-70^{\circ} \mathrm{C} ; 0.5 \mathrm{ml}$ volumes were mixed with $0.1 \mathrm{ml}$ of a $12 \%$ solution of polyethylene glycol

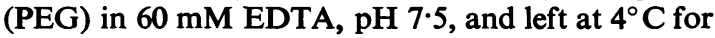

Received for publication 2 January 1979
18 hours. The precipitate was washed with $2 \%$ PEG and redissolved in $0.5 \mathrm{ml}$ of barbitone buffered saline. IgG, Clq, and IgA were measured in the dissolved pellet (Clayton et al., 1977) as was the remaining $\mathrm{Clq}$ in the supernatant after the first centrifugation. Results were expressed as the amount of the total C1q and immunoglobulin precipitated, and the normal range was constructed from a study of healthy adult donors. Results were considered abnormal if the precipitated value was more than 2 standard deviations greater than the mean for normal controls. The laboratory studies were all carried out without knowledge of the clinical details of the patients studied.

\section{Patients}

Patients were included in the study after renal biopsy, which was performed for standard clinical indications, for example, presentation with nephrotic syndrome, recurrent haematuria, deteriorating renal function, or as part of the investigation of systemic disease. Renal biopsies were carried out on 48 patients, and all of these provided material for examination by light microscopy and for immunofluorescence. In the majority, electron microscopy was also carried out.

\section{HISTOLOGY}

\section{Classification of glomerulonephritis}

Cases showing morphological changes of glomerulonephritis were classified as follows:

(1) Mesangial proliferative glomerulonephritis: Glomeruli showed a generalised increase of mesangial matrix with or without a diffuse increase in 
mesangial cellularity; widely patent capillary loops showed no basement membrane thickening. Immunofluorescent and electron-dense deposits, if present, were restricted to mesangium.

(2) Mesangiocapillary glomerulonephritis (West et al., 1965): All glomeruli showed some change with a mixture of mesangial proliferation and thickening of capillary walls varying in extent, together with narrowing of capillary lumens and, in some cases, increased lobulation of the tuft. Immunofluorescence showed granular C3 and IgG deposits in loops and mesangia, and electron dense deposits were present in subendothelial and mesangial sites and sometimes within the membrane. This category included one case with features of 'dense deposit disease' (Habib et al., 1975).

(3) Focal and segmental proliferative glomerulonephritis: This category included cases showing abnormalities of one or more segments of the glomerular tuft, other parts of the glomerulus appearing normal. This corresponds with the term 'local' of other authors (Heptinstall and Joekes, 1959). In some cases the light microscopical changes, consisting of clustering of mesangial nuclei and increase in mesangial matrix, were confined to segments of the tuft with or without capillary lumen obliteration, but, in many, segmental necrosis, focal hyalinisation, and crescent formation were present. Immunofluorescent and ultrastructural findings were usually localised to the area of light microscopic abnormality.

\section{Results}

The results of the study of CIC and renal biopsy are presented in Table 1. Of the total of 31 patients who had immunoglobulin deposits identified by immunofluorescence in the renal biopsy specimens, 23 also had CIC. No deposits were seen in 17 , and in only four of these patients were immune complexes detected in the circulation $\left(\chi^{2} 11.45 ; \mathrm{P}<0.01\right)$. Of the group of 29 patients with glomerulonephritis not associated with systemic disease, 18 had immunofluorescent deposits, 10 of whom had CIC (55\%).

In the 27 patients with CIC, IgG alone was detected in the immune complexes in 10 and IgA alone in four. Both IgG and IgA were found in seven cases, and in four cases neither immunoglobulin was found. In two patients at the beginning of the study the composition of the complexes was not characterised. No clear correlation was found between the immunoglobulin content of the CIC and that of the immunofluorescent deposit.

Six of the 12 patients with mesangiocapillary glomerulonephritis with immunofluorescent deposits had CIC, as did three of the five patients with focal and segmental proliferative glomerulonephritis. No deposits were seen in the seven patients with

Table 1 Analysis of results of diagnosis and immunofluorescent and immune complex findings

\begin{tabular}{|c|c|c|c|}
\hline Diagnosis & $\begin{array}{l}\text { Number } \\
\text { of } \\
\text { patients }\end{array}$ & $\begin{array}{l}\text { Immunofluorescent } \\
\text { positive deposits }\end{array}$ & $\begin{array}{l}\text { Immune } \\
\text { complexes } \\
\text { detected in sera }\end{array}$ \\
\hline \multicolumn{4}{|l|}{ Glomerulonephritis without other disease } \\
\hline Mesangiocapillary glomerulonephritis & 13 & 12 & 6 \\
\hline Mesangial proliferative glomerulonephritis & 7 & 0 & 2 \\
\hline Focal and segmental proliferative glomerulonephritis & 6 & 5 & 3 \\
\hline Minimal change glomerulonephritis & 1 & $\mathbf{0}$ & 1 \\
\hline Rapidly progressive crescentic glomerulonephritis & 1 & 1 & 1 \\
\hline \multirow[t]{2}{*}{ Unclassified end-stage glomerulonephritis } & 1 & 0 & 0 \\
\hline & $\overline{29}$ & $\overline{18}$ & $\overline{12}$ \\
\hline \multicolumn{4}{|l|}{ Glomerulonephritis with systemic disease } \\
\hline Systemic lupus erythematosus & 8 & 8 & 8 \\
\hline Mixed connective tissue disease & 1 & 1 & 1 \\
\hline Wegener's granulomatosis & 1 & 1 & 1 \\
\hline Subacute bacterial endocarditis & 1 & 1 & 1 \\
\hline \multicolumn{4}{|l|}{ Non-glomerular renal disease } \\
\hline Amyloid & 3 & 1 & 1 \\
\hline Interstitial nephritis & 1 & $\mathbf{0}$ & $\mathbf{0}$ \\
\hline Hypertension & $i$ & $\mathbf{0}$ & $\mathbf{0}$ \\
\hline Diabetes mellitus & 1 & $\mathbf{0}$ & $\mathbf{0}$ \\
\hline Myeloma & i & $\mathbf{0}$ & 1 \\
\hline Takayasus arteritis & 1 & 1 & 1 \\
\hline Total & 48 & 31 & 27 \\
\hline $\begin{array}{l}\text { Control patients (no biopsy) } \\
\text { ( } 25 \text { patients with uninfected renal stones, the remainder with } \\
\text { reflux, loin pain, or psychological problems) }\end{array}$ & 44 & & 5 \\
\hline
\end{tabular}


Table 2 Serial studies of circulating immune complexes in patients for whom more than five estimations were obtained

\begin{tabular}{|c|c|c|}
\hline Diagnosis & Patient & Serial estimations \\
\hline Mesangiocapillary glomerulonephritis & $\begin{array}{l}\text { JB } \\
\text { DC } \\
\text { JC } \\
\text { MG } \\
\text { JU } \\
\text { FM }\end{array}$ & $\begin{array}{l}---+----+++- \\
+--++- \\
--+--\overline{-} \\
-----+ \\
----++++++++++ \\
++++++++\end{array}$ \\
\hline Focal and segmental proliferative glomerulonephritis & RM & $\begin{array}{l}+++-- \\
+--++\end{array}$ \\
\hline Mesangial proliferative glomerulonephritis & $\begin{array}{l}\text { KG } \\
\text { MG } \\
\text { DW }\end{array}$ & $\begin{array}{l}+---+ \\
-------+++-+- \\
++----\end{array}$ \\
\hline Minimal change disease & KT & +--++- \\
\hline Systemic lupus erythematosus & $\begin{array}{l}\text { BA } \\
\text { MY }\end{array}$ & $\begin{array}{l}-+-++-++++--+++ \\
--+-+----\end{array}$ \\
\hline $\begin{array}{l}\text { Subacute bacterial endocarditıs } \\
\text { Wegener's granulomatosis } \\
\text { Amyloid }\end{array}$ & $\begin{array}{l}\text { MC } \\
\text { GB } \\
\text { MS }\end{array}$ & $\begin{array}{l}++++-+-+++ \\
+++++++-- \\
+---++\end{array}$ \\
\hline
\end{tabular}

Each + or - sign represents one estimation. Studies were done at intervals of at least four weeks. + implies levels more than two standard deviations above the laboratory normals.

mesangial proliferative glomerulonephritis, but circulating complexes were seen in two, one of whom was recovering from acute glomerulonephritis. Also in the one patient (in relapse) with the minimal change steroid responsive nephrotic syndrome who was submitted to biopsy, CIC were present (Table 1). Eight patients with systemic lupus erythematosus and one each with mixed connective tissue disease, Wegener's granulomatosis, and subacute bacterial endocarditis all had evidence of both deposited and circulating complexes, as did one of three patients with amyloidosis and a patient with Takayasus' arteritis with renal involvement.

\section{SERIAL STUDIES OF IMMUNE COMPLEX}

\section{LEVELS}

Serial studies of CIC were done in 17 patients (Table 2); in 16, levels of CIC varied during the period of study. In one patient with mesangiocapillary glomerulonephritis (JB) there were four changes, and in a patient with systemic lupus (BA), seven. The majority of patients ran a stable course, and it was therefore rarely possible to make meaningful correlations between immune complex levels and clinical events. However, in some cases changes in immune complex status preceded clinical events (Fig. 1); here appearance and persistence of CIC were associated with a rapid decline in renal function. In the one patient with minimal change disease in this series of adults, CIC were detected on two of the three occasions on which he was in relapse (Table 3). In the patient with Wegener's granulomatosis, disappearance of circulating complexes coincided with a loss of proteinuria. Conversely, in a patient presenting with nephrotic syndrome due to mesangial

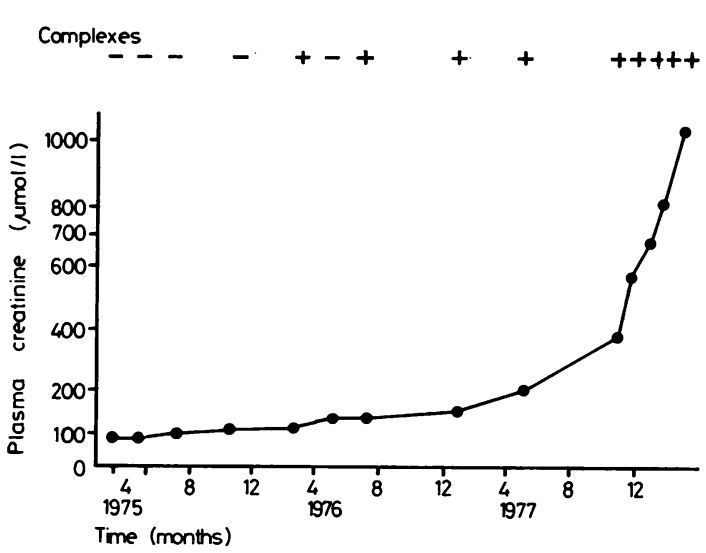

Fig. 1 A patient with mesangiocapillary dense deposit disease in whom appearance and persistence of CIC preceded decline in renal function.

proliferative glomerulonephritis (Fig. 2), the appearance of detectable levels of CIC did not impede resolution of proteinuria or cause any impairment of renal function. He was not receiving steroids or any other immunosuppressive agents.

\section{Discussion}

The reported incidence of demonstration by different workers of CIC in glomerulonephritis varies with the method of measurement and the selection of patients. In our group of patients with glomerulonephritis without other disease we found that 13 out of 29 patients $(45 \%)$ had CIC at the time of study. If only those patients with immunofluorescent 
Table 3 Relationship between amount of proteinuria and presence or absence of CIC in a patient with minimal change disease

\begin{tabular}{lcl}
\hline Date & $\begin{array}{l}\text { Proteinuria } \\
(\mathrm{mg} / 100 \mathrm{ml})\end{array}$ & Complexes \\
\hline January 76 & 30 & - \\
April 76 & 300 & + Relapse \\
August 77 & 300 & - Relapse \\
October 77 & 300 & + Relapse \\
January 78 & 0 & - \\
\hline
\end{tabular}

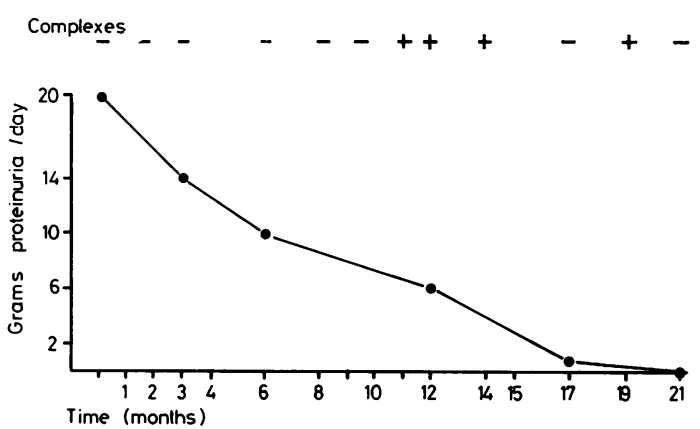

Fig. 2 Amount of proteinuria in relation to presence or absence of CIC in a patient with mesangial proliferative glomerulonephritis.

deposits are considered our incidence becomes 10 out of $18(55 \%)$. These figures compare with $39 \%$ of 36 patients reported by Woodroffe et al. (1977) for the incidence of CIC in primary glomerulonephritis using the combined results of three different methods of measuring CIC. Stühlinger et al. (1976) reported that $48 \%$ of 60 patients with glomerulonephritis had CIC. Rossen et al. (1976) found that only $18 \%$ of 100 glomerulonephritics had circulating complexes. Border et al. (1977) also used two methods to detect CIC in patients with adult idiopathic nephrotic syndrome and found an incidence of $48 \%$. Pussell et al. (1978), in a study of the value of immune complex assays, found that patients with systemic disease such as systemic lupus erythematosus had a higher incidence of circulating complexes $(60 \%)$ than did those with isolated nephritis, for example, $38 \%$ in membranous glomerulonephritis. A previous report from this laboratory gave an incidence of $37 \%$ for circulating complexes in glomerulonephritis measured by an anticomplementary test (Johnson et al., 1975).

All of the 11 patients with glomerulonephritis associated with systemic disease had complexes demonstrated both in the serum and in tissue.

The serial studies of immune complex levels were of interest because in some cases it was possible to correlate variation in circulating complex levels with clinical events. In addition, those cases in which no such correlation obtained may throw light on the relatively low incidence of CIC found in all series of glomerulonephritis so far reported; if complex levels vary it may be that levels are low at the time of biopsy. Pussell et al. (1978), in a group of patients with either systemic disease such as lupus and vasculitis or rapidly progressive immune complex glomerulonephritis, found a correlation between CIC concentration and disease activity. Other workers (Rossen et al., 1976; Woodroffe et al., 1977) have also reported fluctuations in the levels of CIC. It is possible that some of the observed changes in immune complex levels are caused by unrelated events, for example, intercurrent infections. The presence and disappearance of complexes in the one patient with minimal change disease appears to correlate with activity. Although many workers have felt that this was not caused by circulating complexes, the association of these with active disease by Levinsky et al. (1978) and the findings in our patient suggest a causal role.

The pathogenesis of glomerulonephritis and the role of immune complexes remain unclear. The development of renal disease may depend not only on the presence of circulating immune complexes but on the ability of the host to clear them. It is possible that once glomerular injury has occurred, non-complexed antigen or antibody is superadded. It is also possible that the kidney in glomerulonephritis is susceptible to deposition of immune complexes because of a defect in mesangial uptake and handling of macromolecular aggregates or complexes. Measurement of immune complexes in renal disease is useful in that it sometimes reflects or predicts disease activity. Also the use of a method, such as the one described here, which is essentially preservative rather than destructive of the complex, opens the way to identification of the antigen.

This work was supported by a Medical Research Council of Great Britain grant to JFM.

\section{References}

Border, W., Abrass, C., Hall, C., Brown, C., Glassock, R., and Coggins, C. (1977). Detection of circulating immune complexes in adult idiopathic nephrotic syndrome (Abstract). Kidney International, 12, 510.

Clayton, R., Haffenden, G., Du Vivier, A., Burton, J., and Mowbray, J. F. (1977). Pityriasis lichenoides-an immune complex disease. British Journal of Dermatology, 97, 629-634.

Cohen, S. L., Mowbray, J. F., and Fisher, C. (1978). Circulating immune complexes in glomerulonephritis. Quarterly Journal of Medicine, 47, 577-578.

Habib, R., Gubler, M. C., Loirat, C., Maiz, H. B., and 
Levy, M. (1975). Dense deposit disease: a variant of membrano-proliferative glomerulonephritis. Kidney International, 7, 204-215.

Heptinstall, R. H., and Joekes, A. M. (1959). Focal glomerulonephritis: a study based on renal biopsies. Quarterly Journal of Medicine, 28, 329-346.

Johnson, A. H., Mowbray, J. F., and Porter, K. A. (1975). Detection of circulating immune complexes in pathological human sera. Lancet, 1, 762-765.

Levinsky, R. J., Malleson, P. N., Barratt, T. M., and Soothill, J. F. (1978). Circulating immune complexes in steroid-responsive nephrotic syndrome. New England Journal of Medicine, 298, 126-129.

Ooi, Y. M., Vallota, E. H., and West, C. D. (1977). Serum immune complexes in membranoproliferative and other glomerulonephritides. Kidney International, 11, 275-283.

Onyewotu, I. I., and Mee, J. (1978). Circulating immune complexes and complement levels in relation to the clinical presentation of Nigerian children with acute poststreptococcal glomerulonephritis. Journal of Clinical Pathology, 31, 817-822.

Pussell, B. A., Lockwood, C. M., Scott, D. M., Pinching, A. J., and Peters, D. K. (1978). Value of immunecomplex assays in diagnosis and management. Lancet, 2, 359-364.
Rossen, R. D., Reisberg, M. A., Singer, D. B., Schloeder, F. X., Suki, W. N., Hill, L. L., and Eknoyan, G. (1976). Soluble immune complexes in sera of patients with nephritis. Kidney International, 10, 256-263.

Stühlinger, W. D., Verroust, P. J., and Morel-Maroger, L. (1976). Detection of circulating soluble immune complexes in patients with various renal diseases. Immunology, 30, 43-47.

West, C. D., McAdams, A. J., McConville, J. M., Davis, N. C., and Holland, N. H. (1965). Hypocomplementemic and normocomplementemic persistent (chronic) glomerulonephritis; clinical and pathologic characteristics. Journal of Paediatrics, 67, 1089-1112.

Wilson, C. B., and Dixon, F. J. (1976). The renal response to immunological injury. In The Kidney, II, edited by B. M. Brenner and F. C. Rector, Jr., p. 864. W. B. Saunders, Philadelphia.

Woodroffe, A. J., Border, W. A., Theofilopoulos, A. N., Götze, O., Glassock, R. J., Dixon, F. J., and Wilson, C. B. (1977). Detection of circulating immune complexes in patients with glomerulonephritis. Kidney International, 12, 268-278.

Requests for reprints to: Dr S. L. Cohen, Department of Medicine, University College Hospital Medical School, University Street, London WC1E 6JJ, UK. 